\title{
An overview of oral health status, socio- economic and behavioral risk factors, and the pattern of tooth loss in a sample of Egyptian rural population
}

Amani Moussa* ED, Eman Ibrahim, Ahmed Esmat, Sherihan Eissa and Magda Ramzy

\begin{abstract}
Background: The lack of adequate data on the oral health status among the Egyptians is a challenging barrier for the assessment and improvement of oral health needs.

Objectives: The aim of this study was to collect data on oral health status among a sample of Egyptian rural population and to assess the possible role of the socio-demographic, socio-economic, and behavioral risk factors on the status of the present dentition (the pattern of tooth loss and edentulism).

Materials and methods: Data was collected from 530 patients with age ranged from 20 to 70 years using a modified World Health Organization (WHO) questionnaire. The questionnaire included information about oral health status, socio-demographic (age and sex), socio-economic (educational levels and income), and behavioral factors (smoking and oral hygiene measures). A complete intra- and extraoral examination and free dental health care services were provided by a team of qualified dental specialists from National Research Centre (NRC). Data was analyzed using chi-square and Spearman's correlation tests, and the significance level was validated at $p<0.05$.

Results: Females comprised $79 \%$ while males were $21 \%$ of the surveyed rural sample. Concerning socio-economic aspects including the level of education and income, it was found that $50 \%$ of the individuals completed their secondary educational levels, followed by illiterates $35.5 \%$ and preparatory levels, while college graduates were minority $4.7 \%$. On the other hand, only $27.5 \%$ of rural had income while $72.5 \%$ of them had no income. Assessment of behavioral risk factors (oral hygiene procedures and smoking) showed that only $34.3 \%$ of the individuals claimed to brush their teeth and only a minority were male smokers (13.8\%). The results demonstrated poor oral health status and increased incidence of partial edentulism (45\%), where Kennedy class III was the most common type (34.6\%).

\section{Conclusions:}

1. Lack of oral hygiene measures specifically tooth brushing is the most significant behavioral risk factor for the poor oral health status and tooth loss in this survey.

2. Sociodemographic and socio-economic factors are influential risk factors for tooth loss.

3. Cigarette smoking was not a main behavioral risk factor that impacts the oral health status in the present survey
\end{abstract}

Keywords: Oral health, Socio-economic factors, Behavioral risk factors, Tooth loss, Rural population

* Correspondence: amani.moussa66@yahoo.com

Fixed and Removable Prosthodontics Department, National Research Centre,

33 El Buhouth Street, Dokki, Cairo 12622, Egypt 


\section{Introduction}

The World Health Organization (WHO) defined oral health as "a state of being free from mouth and facial pain, oral and throat cancer, oral infection and sores, periodontal disease, tooth decay, tooth loss, and other diseases and disorders that limit an individual's capacity in biting, chewing, smiling, speaking, and psychosocial wellbeing" (World Health Organization 2018).

Good oral health is an integral part of the individual's overall health. In the developed countries, the dental public health is concerned with the improvement of oral health by minimizing social and economic inequalities and facilitating the access to effective prevention programs (Bansal et al. 2015; Schwendicke et al. 2015).

However, in the developing countries, sociodemographic and socio-economic factors such as age, sex, and area of residence along with poverty and lack or low educational level are main influencing factors that negatively impacted oral health. In addition to the previous factors, the absence of dental services within the primary health care centers leads to limited or no access to effective dental care (Narayan et al. 2016). As a result, an increase in the proportion of oral diseases and tooth loss will be expected.

Dental caries and periodontitis are the most common oral diseases which may result in tooth loss. According to WHO databanks, dental caries is the most predominant disease with a higher percentage followed by periodontal disease (World Health Organization 2012). Despite the fact that both diseases are initiated by oral pathogens, dietary habits and behavioral risk factors such as oral hygiene procedures and smoking are important modifying factors that influence the progression of such diseases (Sonkesariya et al. 2014).

Tooth loss does not only affect the individual's health but also affects his quality of life (Xie and Ainamo 1999; Hewlett et al. 2015). The role of sociodemographic, socioeconomic, and behavioral risk factors on tooth loss and edentulism has been well documented in literature. As it was reported in several cross-sectional studies, it was found that tooth loss and edentulism is consistent with sex, age, and areas of residence (Peltzer et al. 2014; Ren et al. 2017; Olofsson et al. 2018).

Since a healthy oral condition is important for general health and because data on oral health status is lacking in Egypt, therefore, the aim of this study was to collect data on oral health status among a sample of Egyptian rural population and to assess the possible role of the socio-demographic, socio-economic, and behavioral risk factors on the pattern of tooth loss and edentulism.

\section{Materials and methods}

\section{Data collection}

A total of 530 individuals with age ranged from 20 to 70 years participated in this survey. This study was conducted at Desia village, Al-Fayoum Governorate, as a part of a 3-year oral health survey supported and funded by the National Research Centre (NRC) in Egypt (Project ID 11010202, Ethical committee approval 16/084) with the cooperation of the Ministry of Health. All patients are informed about the practical steps of this study and signed approval consent.

In this survey, data was collected using a modified WHO questionnaire (Oral Health Assessment Form for Adults, 2013) from patients visiting NRC mobile dental clinics. The questionnaire included information about socio-demographic, socio-economic, and behavioral factors (oral hygiene behavior and smoking).

\section{Dental services}

Free dental health care services were provided by a team of qualified dental specialists from the Oral and Dental Research Division, National Research Centre, a complete intra- and extraoral examination. Necessary dental treatment including extraction, scaling and dental fillings was performed. Toothbrushes, toothpaste, mouth wash, and a simplified booklet on oral health education were distributed for all patients' receiving dental care.

\section{Statistical analysis}

Descriptive and analytical statistics were used to determine the different variables (socio-demographic, socioeconomic, and behavioral factors) and the status of the present dentition. Data was analyzed using SPSS 22@, graph pad, Excel 2019, and presented as percentages in tables. Chi-square test was performed to compare between two or more variables while Spearman's correlation test $(r)$ was performed to correlate different variables $(\mathrm{r}$ value $=0.3$ represnts a weak positive correlation). The significance level was validated at $p<0.05$.

\section{Results}

Socio-demographic (age, sex, and residence), socioeconomic (education, income, and treatment place), and behavioral risk factors (oral hygiene measures and smoking) were presented in Tables 1, 2, 3, 4, 5, 6, and 7).

\section{Socio-demographic and socio-economic factors}

Regarding the age of the surveyed individuals, it was found that the percentage of individuals aged below 44 years old were $(68.6 \%)$ and those above it were $31.4 \%$. Assessment of oral health status of the surveyed sample demonstrated that the majority of the individuals had poor oral health status (Table 1). Performing Spearman's correlation test showed that there was a weak positive 
Table 1 Correlation between oral health status and the age of the surveyed sample

\begin{tabular}{|c|c|c|c|c|c|c|}
\hline \multirow{2}{*}{$\begin{array}{l}\text { Age } \\
\text { range }\end{array}$} & \multicolumn{4}{|c|}{ Oral hygiene } & \multirow{2}{*}{$\begin{array}{l}\text { Correlation } \\
(r)\end{array}$} & \multirow{2}{*}{$\begin{array}{l}p \\
\text { value }\end{array}$} \\
\hline & Excellent & Very good & Good & Poor & & \\
\hline $18-70$ & (0) & $3(0.5 \%)$ & $131(24.6 \%)$ & 397 (74.9\%) & 0.393 & $0.000^{*}$ \\
\hline
\end{tabular}

correlation between the age and oral health status in the surveyed sample and the difference was statistically significant $(p<0.05)$.

The percentages of males and females who participated and sought dental treatment from the village were not equal, where females comprised 417 (78.7\%) and males were $113(21.3 \%)$ only (Table 2). Poor oral health status was common among both sexes and the results were statistically insignificant $(p>0.05)$.

Concerning educational levels, the results revealed that nearly half of the individuals have finished their secondary/diploma level and illiterates were slightly more than one third, while college graduates were only $4.7 \%$ and no higher education level was found among the surveyed sample. Performing Spearman's correlation test $(r)$ to correlate between the oral health status and educational level (Table 3) revealed a weak positive result, and it was statistically significant $(p<0.05)$.

Regarding the income in the surveyed sample, it was found that most of the individuals had no income at all, 72.5\%. 9.5\% have no fixed income and only $18 \%$ had fixed income. Comparing income distribution among both sexes, it was found that almost all of the females had no income (Table 4 ) and the result was statistically significant $(p<0.05)$.

\section{Socio-behavioral factors}

Smoking and daily oral hygiene measures were evaluated and presented in Tables 5 and 6, respectively. As shown in Table 5 only 73 individuals (13.7\%) were cigarettes smoker and they were all males. Poor oral health was the main finding with higher percentages for nonsmoker compared to the smoker category. Very good and good oral health was found among the non-smoker group, and the results were statistically insignificant $(p>$ $0.05)$.

Table 2 Oral health status according to sex

\begin{tabular}{llllll}
\hline Sex distribution & \multicolumn{2}{l}{ Oral health status } & $p$ \\
\cline { 3 - 5 } & & Very good & Good & Poor & value \\
\hline Male & $113(21.3 \%)$ & 0 & $23(20 \%)$ & $90(80 \%)$ & 0.6 \\
Female & $417(78.7 \%)$ & $2(0.46 \%)$ & $108(25.89 \%)$ & $307(73.61 \%)$ & \\
\hline
\end{tabular}

$p$ value statistically insignificant
Evaluation of oral hygiene measures showed that 182 (34.3 5\%) brushed their teeth and 348 (65.7\%) did not. Poor oral health status was the result among both who claimed to brush their teeth and those who did not. Statistical analysis revealed significance differences $(p<0.05)$ as presented in Table 6 .

\section{Dentition status}

Regarding the status of the present dentition statistical analysis displayed that approximately $54.5 \%$ (288) of the individuals were dentulous, $1 \%$ (5) were completely edentulous, and $45 \%$ (239) were partially edentulous. According to the Kennedy classification for partial edentulism, the most common type was Kennedy class III, followed by class II, class I, and the least was class IV. Statistical analysis of the results revealed significant differences $(p<0.05)$ (Table 7).

\section{Discussion}

The influence of socio-demographic (age, sex, and area of residence), socio-economic factors (level of education and income), and behavioral risk factors (smoking and tooth brushing) on the oral health was investigated in this survey.

Although there is a great effort to improve general health in Egypt, oral health problems do not receive the required attention. Data on oral health status among different urban and rural populations is lacking. Educating people about the importance of oral health, risk factors of oral diseases, and addressing these issues within the care programs are considered a key to control and/or to prevent incidence of the oral diseases, especially caries and periodontitis and thereby aiming to improve oral health status in a developing country like Egypt.

In the present survey, Desia village was chosen as it is nearly deprived of primary dental health care services. The outcomes of the present survey obviously demonstrated that age, sex, and rural residence have greatly impacted the oral health status among the surveyed sample. Poor oral health status was a common finding with a positive correlation between oral health status and age. Such results are in agreement with a previous study that reported poor oral health is more common among elderly, where compromised general health is usually accompanied by deteriorated oral health status (Gil-Montoya et al. 2015). 
Table 3 Oral health status among different educational levels

\begin{tabular}{|c|c|c|c|c|c|c|}
\hline \multirow[t]{2}{*}{ Level of education, $\%$} & & \multicolumn{4}{|c|}{ Oral health status } & \multirow{2}{*}{$\begin{array}{l}p \\
\text { value }\end{array}$} \\
\hline & & Very good & Good & Poor & Correlation $(r)$ & \\
\hline Illiterate & $188(35.5 \%)$ & $0(0 \%)$ & $15(8 \%)$ & $173(92 \%)$ & 0.359 , moderate & $0.000^{*}$ \\
\hline Primary & $10(1.9 \%)$ & $0(0 \%)$ & $5(50 \%)$ & $5(50 \%)$ & & \\
\hline Preparatory & $45(8.5 \%)$ & $0(0 \%)$ & $15(33.3 \%)$ & $30(66.7 \%)$ & & \\
\hline Secondary /diploma & $262(49.3 \%)$ & $2(1 \%)$ & $91(34.6 \%)$ & $169(64.4)$ & & \\
\hline College & $25(4.7 \%)$ & $0(0 \%)$ & $5(20 \%)$ & $20(80 \%)$ & & \\
\hline Higher & $0(0 \%)$ & $0(0 \%)$ & $0(0 \%)$ & $0(0 \%)$ & & \\
\hline
\end{tabular}

${ }^{*} p$ value statistically significant

In the present survey, the majority of the examined individuals were females $(78.7 \%)$ which could be considered a limiting factor that might influence the results of this study. The free dental services offered by NRC could possibly encourage more female patients from the village to seek treatment especially that almost all of them have no income compared to males. However, poor oral status was found among both sexes. This outcome is in contrary to Wiener et al. (2012) who found that women had significantly better oral hygiene practices compared to men. They attributed this finding to that women were more concerned about appearance and health.

Regarding the educational levels, the results showed that nearly half of individuals completed their secondary/diploma education and slightly more than one third were illiterate and less than $5 \%$ finished their college education. As a higher level of education was achieved, the oral health status was slightly improved in the present study. This outcome is in harmony with previous studies that reported better oral health status was found among individuals who achieved higher educational levels. They also found that a higher level of education was associated with better income, knowledge about oral diseases, and their preventive measures as well as the ability to obtain dental care services (Schluter et al. 2015; CDC n.d.; Gomes et al. 2015).

In this survey, the majority of individuals had no income with females constituting $98 \%$ of them. Only less than one-fifth of the surveyed sample had fixed income while less than $10 \%$ had no fixed income. A similar

Table 4 Income distribution among males and females

\begin{tabular}{lllll}
\hline Type of income & & \multicolumn{2}{l}{ Sex and income distribution } & \multirow{2}{c}{$\begin{array}{c}p \\
\text { value }\end{array}$} \\
\cline { 3 - 4 } & & Female & Male & \\
\hline Fixed income & $96(18 \%)$ & $63(65.8 \%)$ & $33(34.2 \%)$ & $0.000^{*}$ \\
No fixed income & $50(9.5 \%)$ & $43(85 \%)$ & $7(15 \%)$ & \\
No income & $384(72.5 \%)$ & $8(2 \%)$ & $376(98 \%)$ & \\
\hline
\end{tabular}

* $p$ value statistically significant outcome was found by Trohel et al. (2016) who revealed that the need for dental care is higher among adults with low socio-economic where financial deficiency was the main reason for not seeking dental treatment.

Among the most important socio-behavioral risk factors that could affect the oral health status are smoking and oral hygiene procedures specifically toothbrushing (Torkzaban et al. 2013; Han and Park 2017).

Smoking has been associated with gingivitis, calculus, and periodontitis. In the present survey, the majority were non-smokers approaching $90 \%$ while only $10 \%$ were male smokers. Unexpectedly, poor oral health was the present finding among the vast majority of nonsmokers. Such a result demonstrated that although smoking is an important risk factor, it is not the main influencing factor in this survey (Torkzaban et al. 2013; Han and Park 2017).

Tooth brushing is a main oral-care procedure to maintain good oral health. Tooth brushing twice a day has become an ordinary behavior in countries like America and Australia (Kumar et al. 2016). In the current survey, only $34.3 \%$ of the surveyed sample claimed to brush their teeth. However, poor oral health status was found among the majority of individuals who claimed to brush their teeth and who actually did not. Similar findings were reported by $\mathrm{Su}$ et al. (2016). They confirmed that improper oral hygiene measures were associated with oral diseases such as caries and periodontal disease.

The occurrence of edentulism provides information about oral health status and dental health system providers (Thomson 2012). In the present survey, tooth loss

Table 5 Oral health status among smokers and non-smokers

\begin{tabular}{llllll}
\hline Cigarette smoking & \multicolumn{3}{l}{ Oral health status } & \multirow{2}{*}{$\begin{array}{l}p \\
\text { value }\end{array}$} \\
\cline { 3 - 5 } & & Very good & Good & Poor & \\
\hline Smoker & $73(13.7 \%)$ & $0(0 \%)$ & $12(16.7 \%)$ & $61(83.3 \%)$ & 0.288 \\
Non-smoker & $457(86.2 \%)$ & $2(0.5 \%)$ & $118(25.8 \%)$ & $337(73.7 \%)$ & \\
\hline
\end{tabular}

$p$ value statistically insignificant 
Table 6 Oral health status and toothbrushing.

\begin{tabular}{|c|c|c|c|c|c|}
\hline \multirow[t]{2}{*}{ Toothbrushing } & & \multicolumn{3}{|c|}{ Oral health status } & \multirow{2}{*}{$\begin{array}{l}p \\
\text { value }\end{array}$} \\
\hline & & Very good & Good & Poor & \\
\hline No toothbrushing & $348(65.7 \%)$ & $3(0.7 \%)$ & $67(19.3 \%)$ & $278(80 \%)$ & $0.039^{*}$ \\
\hline Toothbrushing & $182(34.3 \%)$ & $0(0 \%)$ & $63(34.7 \%)$ & $119(65.3 \%)$ & \\
\hline
\end{tabular}

${ }^{*} p$ value statistically significant

occurred nearly in half of the sample with the highest proportion for partial edentulism, where Kennedy class III was the most occurring type of partial edentulism encountered. This finding could be attributed to the absence of oral hygiene practices and consequently poor oral health status, low socio-economic status, and a lack of accessible and affordable dental treatment instead of teeth extraction (Medina-Solís et al. 2014; Olofsson et al. 2017). Furthermore, Muneeb (2013) and Jeyapalan and Krishnan (2015)) attributed tooth loss to lack of awareness and inadequate dental care services.

\section{Conclusions}

Within the limitation of this survey, the following results were concluded:

1. Lack of oral hygiene measures specifically toothbrushing is the most significant behavioral risk factor for the poor oral health status and tooth loss in this survey.

2. Sociodemographic factors (age, sex, and rural residence) and socio-economic factors (level of education and income) are influential risk factors for tooth loss.

3. Cigarette smoking was not a main behavioral risk factor that impacts the oral health status in the present survey.

4. The incidence of partial edentulism among the surveyed Egyptian rural sample is high.

\section{Recommendations}

Further hard work remains obligatory to extend the awareness about oral health and hygiene practicing and to inspire the Egyptian population to develop healthier oral habits. Adequate oral hygiene measure mainly tooth brushing will help to improve oral health status by reducing the incidence of caries and periodontal diseases and thereby teeth loss.

\section{Abbreviations \\ WHO: World Health Organization}

\section{Acknowledgements}

National Research Centre (NRC), Cairo, Egypt

\section{Authors' contributions}

All authors certify that they have participated sufficiently in contributing to the intellectual content, concept, and design of this work and the analysis and interpretation of the data, as well as writing of the manuscript, to take public responsibility for it, and they have agreed to have their names in the listed order as a contributor of this research. All authors read and approved the final manuscript.

\section{Funding}

This research was a part of a 3-year project funded and supported by National Research Centre (NRC), Cairo, Egypt. Project ID 11010202, entitled "Oral health status its relation to socio-economic and behavioral risk factors in Egypt".

\section{Availability of data and materials}

This article is under the terms of the creative commons AttributionNoncommercial-No Derives License, which permits the use and distribution in any medium, provided the original work is properly cited, the use is noncommercial, and no modifications or adaptations are made. Materials were available in the market and data was collected in a smooth manner.

\section{Consent for publication}

The research manuscript is not concurrently under consideration for publication in another journal. All named authors were involved in the work leading to the publication of the paper, and they have read the paper before it is submitted for publication.

Competing interests

The authors declare that they have no competing interests.

Table 7 Dentition status and pattern of tooth loss

\begin{tabular}{|c|c|c|c|c|c|c|c|}
\hline \multirow[t]{2}{*}{ Dentition status } & & & & & \multicolumn{2}{|c|}{ Dentition status and sex distribution } & \multirow{2}{*}{$\begin{array}{l}p \\
\text { value }\end{array}$} \\
\hline & & & & & Males & Females & \\
\hline Dentulous & $54.3 \%$ & & & & 65 (22.6\%) & $223(77.4 \%)$ & $0.00^{*}$ \\
\hline Edentulous & $1 \%$ & & & & $1(20 \%)$ & $4(80 \%)$ & \\
\hline \multirow[t]{4}{*}{ Partially edentulous } & $(45 \%)$ & Kennedy classification & Class I & $2.9 \%$ & $10(66.6 \%)$ & $5(33.4 \%)$ & \\
\hline & & & Class $\|$ & $6.2 \%$ & $28(84.8 \%)$ & $5(15.1 \%)$ & \\
\hline & & & Class III & $34.8 \%$ & $14980.9 \%)$ & $35(19.1 \%)$ & \\
\hline & & & Class IV & $1 \%$ & $5(100 \%)$ & $0(0 \%)$ & \\
\hline
\end{tabular}


Received: 8 December 2019 Accepted: 10 January 2020

Published online: 30 January 2020

\section{References}

Xie Q, Ainamo A (1999) Association of edentulousness with systemic factors in elderly people living at home. Comm Dent Oral Epidemiol 27(3):202-2019

Bansal A, Ingle NA, Kaur N, Ingle E (2015) Recent advancements in fluoride: A systematic review. J Int Soc Prev Community Dent 5:341-346

CDC. Disparities in Oral Health. n.d. Available online: https://www.cdc.gov/ oralhealth/oral_health_disparities/ index.htm (Accessed on 30 Nov 2019)

Gil-Montoya JA, de Mello ALF, Barrios R, Gonzalez-Moles MA, Bravo M (2015) Oral health in the elderly patient and its impact on general well-being: a nonsystematic review. ClinInterv Aging 10:461-467

Gomes A, Silva E, Gonçalves S, Huhtala M, Martinho F, Gonçalves S, Torres C (2015) Relationship between patient's education level and knowledge on oral health preventive measures. Inter Dent Med J of Adv Res 1:1-7

Han K, Park JB (2017 Feb) Association between oral health behavior and periodontal disease among Korean adults: the Korea national health and nutrition examination survey. Medicine (Baltimore) 96(7):e6176

Hewlett SA, Yawson AE, Calys-Tagoe BN, Naidoo N, Martey P, Chatterji S, Kowal P, Mensah G, Minicuci N, Biritwum RB (2015) Edentulism and quality of life among older Ghanaian adults. BMC Oral Health 15:48

Jeyapalan V, Krishnan C (2015) partial edentulism and its correlation to age, gender, socio-economic status and incidence of various Kennedy's classes- a literature review. J Clin Diagn Res 9(6):14-17

Kumar S, Tadakamadla J, Johnson NW (2016) Effect of toothbrushing frequency on incidence and increment of dental caries: a systematic review and metaanalysis. J Dent Res 95:1230-1236

Medina-Solís CE, Pontigo-Loyola AP, Pérez-Campos E, Hernández-Cruz P, AvilaBurgos L, Mendoza-Rodríguez M, Maupomé G (2014) Edentulism and other variables associated with self-reported health status in Mexican adults. Med Sci Monit 20:843-852

Muneeb A (2013) Causes and pattern of partial edentulism/ exodontia and its association with age and gender: semirural population, Baqai Dental College, Karachi, Pakistan. Idjsr 1(3):13-18

Narayan A, Thomas SJ, Daniel A, Fatima S, Mathew RA (2016) An overview of oral health in India: current scenario and challenges. Int J Oral care and research 4(4):280-283

Olofsson H, Ulander EL, Gustafson Y, Hörnsten C (2017) Association between socioeconomic and health factors and edentulism in people aged 65 and older - a population-based survey. Scand J Public Health. 46(7):690-698

Olofsson H, Ulander EL, Gustafson Y, Hörnsten C (2018) Association between socioeconomic and health factors and edentulism in people aged 65 and older - a population-based survey. Scand J Public Health 46(7):690-698

Peltzer K, Hewlett S, Yawson AE, Moynihan P, Preet R, Wu F, Guo G, Arokiasamy P, Snodgrass JJ, Chatterii S, Engelstad ME, Kowal P (2014) Prevalence of loss of all teeth (edentulism) and associated factors in older adults in China, Ghana, India, Mexico, Russia and South Africa. Int J Environ Res Public Health 11(11):11308-11324

Ren C, McGrath C, Yang Y (2017) Edentulism and associated factors among community-dwelling middle-aged and elderly adults in China. Gerodontology. 34(2):195-207. https://doi.org/10.1111/ger.12249

Schluter P, Lee M, Hamilton G, Coe G, Messer-Perkins H, Smith B (2015) Keep on brushing: a longitudinal study of motivational text messaging in young adults aged 18-24 years receiving work and income support. J Public Health Dent 75(2):118-125

Schwendicke F, Dörfer CE, Schlattmann P, Foster Page L, Thomson WM, Paris S (2015) Socioeconomic inequality and caries: a systematic review and metaanalysis. Clin Rev 94(1):10-18

Sonkesariya S, Jain D, Shakya P, Agrawal R (2014) Prevalence of dentulism, partial edentulism, and complete edentulism in rural and urban population of Malwa region of India: a population based-study. Int J Prosthodont Restor Dent 4:112-119

Su L, Liu W, Xie B et al (2016) Toothbrushing, blood glucose and HbA1c: findings from a random survey in Chinese population. Sci Rep 6:28824

Thomson WM (2012) Monitoring edentulism in older New Zealand adults over two decades: a review and commentary. Int J Dent 2012:375407

Torkzaban P, Khalili Z, Ziaei N (2013) Smoking and periodontal diseases. Avicenna J Dent Res 5(2):e20218
Trohel G, Bertaud-Gounot V, Soler M, Chauvin P, Grimaud O. Socio-economic determinants of the need for dental care in adults. PLoS One 2016; 11(7): e0158842

Wiener RC, Wu B, Crout RJ, Plassman BL, McNeil DW, Wiener MA, Kao E, Caplan DJ (2012) Hygiene self-care of older adults in West Virginia: effects of gender. J Dent Hyg 86(3):231-238

World Health Organization (2012) Oral health, vol 2018

World Health Organization (2013). Oral health surveys: basic methods - 5th edition, Annex 1

World Health Organization (2018) Oral health, vol 2018

\section{Publisher's Note}

Springer Nature remains neutral with regard to jurisdictional claims in published maps and institutional affiliations.

\section{Submit your manuscript to a SpringerOpen ${ }^{\circ}$ journal and benefit from:}

- Convenient online submission

- Rigorous peer review

- Open access: articles freely available online

- High visibility within the field

- Retaining the copyright to your article

Submit your next manuscript at $>$ springeropen.com 